\title{
Selenium - a fascinating antioxidant of protective properties
}

\author{
Małgorzata Kiełczykowska”, A-E, Joanna Kocot ${ }^{1, C-E}$, Marek Paździor ${ }^{2, B-D}$, Irena Musik' ${ }^{1, B-D, F}$ \\ ${ }^{1}$ Chair and Department of Medical Chemistry, Medical University of Lublin, Poland \\ ${ }^{2}$ Traumatic-Orthopaedic and Spine Surgery Ward of Independent Public Health Care Centre, Puławy, Poland \\ A - research concept and design; $\mathrm{B}$ - collection and/or assembly of data; $\mathrm{C}$ - data analysis and interpretation; \\ $\mathrm{D}$ - writing the article; $\mathrm{E}$ - critical revision of the article; $\mathrm{F}$ - final approval of the article
}

\section{Address for correspondence}

Joanna Kocot

E-mail: joanna.kocot@umlub.pl

Funding sources

None declared

\section{Conflict of interest}

None declared

Received on March 9, 2016

Reviewed on August 31, 2016

Accepted on November 18, 2016

\begin{abstract}
Selenium is a trace element which fulfils important functions in the organism. Its deficit may cause acute disorders, but an overdose can also lead to severe consequences. The functions of selenium in the organism are mainly connected with its antioxidant properties, as it is an essential part of important antioxidant enzymes. Disturbances of oxidant balance have been found to be involved in the activity of numerous harmful factors as well as in the pathogenesis of diverse illnesses. Selenium administration has proved to be effective against the toxicity of many agents and the side effects of drugs. However, the narrow range between therapeutic and toxic doses of selenium, as well as the dependence of its effect on the applied form, dose and method of treatment, makes the choice of the most effective supplement a very complex issue. Divergent forms of selenium are still being studied, including both inorganic and organic compounds as well as Se-enriched natural products. The newest research has also involved selenium nanoparticles. The aim of this review is to present the great potential of selenium for protecting the organism against a wide variety of environmental pollutants, drugs and physical factors.
\end{abstract}

Key words: oxidative stress, selenium, drug-related side effects, protective agents

DOI

10.17219/acem/67222

\section{Copyright}

Copyright by Author(s)

This is an article distributed under the terms of the

Creative Commons Attribution Non-Commercial License

(http://creativecommons.org/licenses/by-nc-nd/4.0/) 


\section{Introduction}

Selenium belongs to trace elements essential for humans. In the body it is involved in numerous processes, among other things immune functions and antioxidant defense. Its deficit may result in cardiac, muscular, osseous, and immune disturbances. ${ }^{1,2}$ The biological functions of selenium result from the occurrence of the selenocysteine amino acid in proteins. The research has revealed that about a hundred selenoproteins can be found in mammal organisms. ${ }^{2}$ The most important of them are the antioxidant enzymes - glutathione peroxidase and thioredoxin reductase, as well as selenoprotein $\mathrm{P}$, responsible for the storage and transport of selenium. ${ }^{3-6}$ Selenium supplementation has been proved to be protective against a very wide range of harmful factors, both chemical, such as drugs exerting severe side effects, heavy metals, carcinogens, mycotoxins, or pesticides, and physical, such as heat stress or magnetic fields. However, the narrow range between therapeutic and toxic doses of selenium, as well as the dependence of its effect on the applied form, dose and method of treatment, make the choice of the most effective supplement a very complex issue. ${ }^{5,7-10}$
The average lethal dose established in animal models for sodium selenite (7 mg Se/kg b.w.) is almost 20 times smaller than that obtained for selenium sulfides, and more than 900 times smaller than for elemental selenium. ${ }^{11}$ According to the US National Academy of Sciences, for adults, $55 \mu \mathrm{g}$ is the recommended daily selenium intake, whereas $400 \mu \mathrm{g}$ is the threshold which should not be exceeded. ${ }^{7}$ The toxic dose for adults was established as more than $700 \mu \mathrm{g} /$ day. ${ }^{12}$ The symptoms of selenium toxicity include fatigue, disturbances in connective tissue as well as in cardiovascular, gastrointestinal, nervous, and respiratory systems. ${ }^{11,13}$ As the interest in selenium and its effects on human health is still growing, diverse compounds of selenium are still being studied, both inorganic and organic, Se-enriched natural products like probiotics, yeast and green tea, as well as selenium nanoparticles. ${ }^{3,8,10,14-18}$ Organic compounds have been widely studied recently due to the similarity of the activity of some of them (e.g., ebselen or diphenyl diselenide) to that shown by glutathione peroxidase. ${ }^{19}$ Diphenyl diselenide has also been proved to possess many beneficial pharmacological properties: anti-hyperglycemic, anti-hyperlipidemic, hepatoprotective, antiulcer, and antidepressant. ${ }^{19,20}$

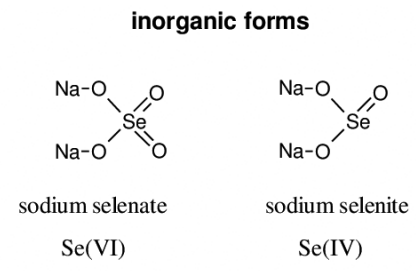

organic forms
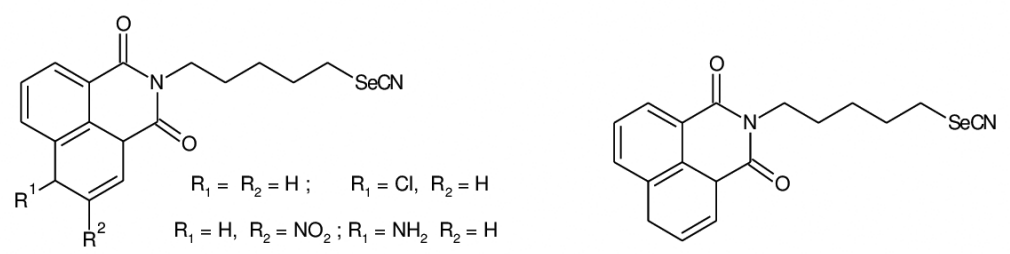

naphtalimide based selenocyanates

2-(5-selenocyanatopentyl)-benzo[de]isoquinoline 1,3-dione

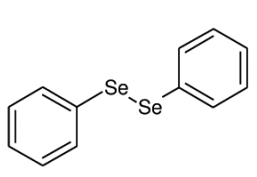

diphenyl diselenide

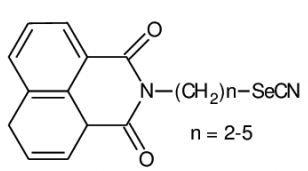

selenocynates

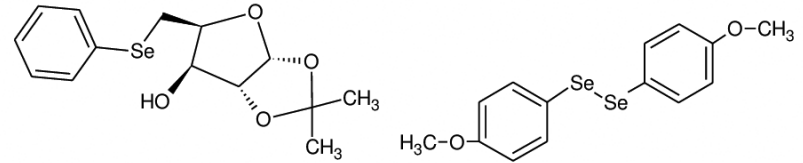

seleno-furanoside

p-methoxyl-diphenyl diselenide

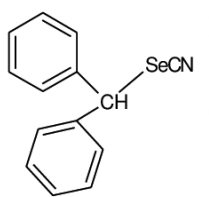

diphenylmethyl selenocyanate<smiles>C[Se]CCC(N)C=O</smiles>

selenomethionine 
The aim of this review is to present the great potential of selenium for protecting the organism against the damage caused by environmental pollutants, drugs and physical factors, as well as the dependence of the selenium impact on the form and model of administration.

\section{Comparison of the effect of different selenium forms on organisms}

The effect of selenium on organisms shows strong dependence on its form. A distinct difference between organic and inorganic compounds has been found. The forms of selenium used are presented in Fig. 1.

Sodium selenite remains the most often studied inorganic form of selenium, containing Se(IV), but other forms are also commonly studied. A comparison of selenite and selenate, containing $\mathrm{Se}(\mathrm{VI})$, was performed on the mycelia of Pleurotus ostreatus exposed to cadmium and silver (1.25 mg/L, $2.5 \mathrm{mg} / \mathrm{L}$ and $5 \mathrm{mg} / \mathrm{L})$. Selenium $(2.5 \mathrm{mg} / \mathrm{L}$ or $5 \mathrm{mg} / \mathrm{L}$ ) prevented the malonyldialdehyde (MDA) increase caused by the metals, but while Se(IV) showed full effectiveness, $\mathrm{Se}(\mathrm{VI})$ was either less effective or even intensified the pro-oxidant processes. ${ }^{21}$

The research more and more often includes selenoorganic compounds - either naturally occurring forms or newly synthesized substances, e.g., selenomethionine, naphthalimide-based selenocyanates, 2-(5-selenocyanatopentyl)-benzo[de]isoquinoline-1,3-dione, diphenyl diselenide, selenofuranoside, p-methoxyldiphenyl diselenide, selenocyanates, and diphenylmethyl selenocyanate. ${ }^{4-6,9,16,17,19,20,22-26}$ The results regarding the comparison of inorganic and organic compounds are not fully consistent, although the newest studies usually reveal

Table 1. Protective effect of selenium against cisplatin toxicity

\begin{tabular}{|c|c|c|c|c|c|}
\hline $\begin{array}{l}\text { Authors, } \\
\text { citation } \\
\text { number }\end{array}$ & $\begin{array}{c}\text { Animals, } \\
\text { way of } \\
\text { administration, } \\
\text { dose, } \\
\text { time of exposure }\end{array}$ & $\begin{array}{l}\text { Harmful effects } \\
\text { of cisplatin }\end{array}$ & $\begin{array}{l}\text { Selenium form, } \\
\text { dose, } \\
\text { method and time } \\
\text { of administration }\end{array}$ & $\begin{array}{l}\text { Effects of selenium } \\
\text { co-administration }\end{array}$ & $\begin{array}{l}\text { Effects } \\
\text { of Se itself }\end{array}$ \\
\hline $\begin{array}{l}\text { Chakraborty } \\
\text { et al. } 2011^{9}\end{array}$ & $\begin{array}{c}\text { mice } \\
\text { intraperitoneally } \\
5 \mathrm{mg} / \mathrm{kg} \text { b.w. } \\
5 \text { days }\end{array}$ & $\begin{array}{c}\text { kidney GST, GPx, CAT, } \\
\text { SOD, GSH } \downarrow \text {; } \\
\text { kidney TBARS, serum creatinine, } \\
\text { blood urea nitrogen } \uparrow\end{array}$ & $\begin{array}{c}\text { synthetic organic } \\
\text { diphenylmethyl } \\
\text { selenocyanate, } \\
3 \text { mg/kg b.w., oral gavage, } \\
2 \text { models: } \\
\text { concomitant treatment } \\
\text { (Se from day } 1 \text { to day 9, and } \\
\text { cisplatin from day } 1 \text { to day 5); } \\
\text { pretreatment } \\
\text { (Se } 7 \text { days before cisplatin, } \\
\text { and then from day } 1 \text { to day 9, } \\
\text { cisplatin from day } 1 \text { to day 5) }\end{array}$ & $\begin{array}{c}\text { kidney GPx, CAT, SOD, } \\
\text { serum creatinine, blood urea } \\
\text { nitrogen }( \pm) \text {; } \\
\text { kidney GSH, GST, TBARS }(+) \text {; } \\
\text { pretreatment model more } \\
\text { effective }\end{array}$ & none \\
\hline $\begin{array}{l}\text { Yazici et al. } \\
2014^{30}\end{array}$ & $\begin{array}{c}\text { rats } \\
\text { intraperitoneally } \\
16 \mathrm{mg} / \mathrm{kg} \\
3 \text { days }\end{array}$ & $\begin{array}{l}\text { drug-caused edema and } \\
\text { subsequently retinal thickness } \\
\text { increase }\end{array}$ & $\begin{array}{c}\mathrm{Na}_{2} \mathrm{SeO}_{3} \\
1.5 \mathrm{mg} \text { of } \mathrm{Se} / \mathrm{kg} \text {, oral gavage } \\
\text { twice daily, for } 5 \text { days } \\
\text { before drug and for } 3 \text { days } \\
\text { concomitantly }\end{array}$ & $\begin{array}{l}\text { selenium reduced the effects } \\
\text { of cisplatin and showed } \\
\text { the antiapoptotic influence }\end{array}$ & not studied \\
\hline $\begin{array}{l}\text { Rezvanfar et al. } \\
2013^{31}\end{array}$ & $\begin{array}{c}\text { rats } \\
\text { intraperitoneally, } \\
\text { single injection } \\
7 \mathrm{mg} / \mathrm{kg} \\
\text { before Se }\end{array}$ & $\begin{array}{c}\text { serum testosterone } \downarrow ; \\
\text { sperm abnormality } \uparrow ; \\
\text { blood and testis lipid } \\
\text { peroxidation } \uparrow ; \\
\text { blood and testis peroxynitrite } \uparrow ; \\
\text { blood and testis SOD, } \\
\text { CAT, GPX } \downarrow\end{array}$ & $\begin{array}{c}\text { selenium nanoparticles } \\
2 \mathrm{mg} / \mathrm{kg} / \text { day, orally } \\
10 \text { days }\end{array}$ & $\begin{array}{c}\text { serum testosterone }( \pm) ; \\
\text { sperm abnormality }( \pm) ; \\
\text { blood and testis lipid } \\
\text { peroxidation }(+) ; \\
\text { blood and testis } \\
\text { peroxynitrite }(+) ; \\
\text { blood and testis SOD, CAT, } \\
\text { GPx (+) }\end{array}$ & none \\
\hline $\begin{array}{l}\text { Wilhelm et al. } \\
2012^{25}\end{array}$ & $\begin{array}{c}\text { mice } \\
\text { intraperitoneally, } \\
\text { single injection } \\
10 \mathrm{mg} / \mathrm{kg} \\
\text { on day } 3\end{array}$ & $\begin{array}{c}\text { plasma urea and plasma } \\
\text { creatinine } \uparrow ; \\
\text { kidney vitamin C, GSH, GST, GPx, } \\
\text { GR, CAT, } \delta \text {-ALA-D } \downarrow\end{array}$ & $\begin{array}{c}\text { p-methoxyl-diphenyl } \\
\text { diselenide } \\
50 \mathrm{mg} / \mathrm{kg} \text { or } 100 \mathrm{mg} / \mathrm{kg} \text {, orally } \\
6 \text { days }\end{array}$ & $\begin{array}{c}\text { lower dose: } \\
\text { plasma urea }( \pm) ; \\
\text { plasma creatinine }(0) ; \\
\text { kidney GSH, GST, GPx, GR, } \\
\text { } \text {-ALA-D }( \pm) \text {; } \\
\text { kidney vitamin C, CAT }(+) \\
\text { higher dose: } \\
\text { plasma urea and plasma } \\
\text { creatinine }( \pm) \text {, } \\
\text { kidney GSH, GST, GPx, GR, } \\
\text { vitamin C, CAT }(+) \\
\text { kidney } \delta-A L A-D( \pm)\end{array}$ & none \\
\hline
\end{tabular}

$\downarrow$ - decrease; $\uparrow$ - increase; (+) - full protection; $( \pm$ ) - partial protection; (0) - lack of protection; GST - glutathione S-transferase; GPX - glutathione peroxidase; CAT - catalase; SOD - superoxide dismutase; GSH - reduced glutathione; TBARS - thiobarbituric acid-reactive substances; GR - glutathione reductase; $\delta$-ALA-D - $\delta$-aminolevulinic dehydratase.. 
Table 2. Protective effect of selenium against toxicity of different drugs

\begin{tabular}{|c|c|c|c|c|c|}
\hline $\begin{array}{l}\text { Authors, } \\
\text { citation } \\
\text { number }\end{array}$ & $\begin{array}{c}\text { Animals, } \\
\text { way of } \\
\text { administration, } \\
\text { dose, } \\
\text { time of exposure }\end{array}$ & $\begin{array}{l}\text { Harmful effects } \\
\text { of drug }\end{array}$ & $\begin{array}{l}\text { Selenium form, } \\
\text { dose, } \\
\text { method and time } \\
\text { of administration }\end{array}$ & $\begin{array}{l}\text { Effects of selenium } \\
\text { co-administration }\end{array}$ & $\begin{array}{l}\text { Effects of } \\
\text { Se itself }\end{array}$ \\
\hline $\begin{array}{l}\text { Gürgen et al. } \\
2013^{32}\end{array}$ & $\begin{array}{c}\text { rats, } \\
\text { cyclophosphamide } \\
\text { intraperitoneally } \\
75 \text { mg/kg b.w. } \\
\text { once a week, for } \\
3 \text { weeks }\end{array}$ & $\begin{array}{l}\text { degeneration of the } \\
\text { ovarian tissue; } \\
\text { serum GSH } \downarrow\end{array}$ & $\begin{array}{c}40 \mathrm{ppm} / \text { day/rat, oral gavage } \\
3 \text { weeks }\end{array}$ & $\begin{array}{l}\text { reducing the degeneration of } \\
\text { ovarian tissue; } \\
\text { serum GSH }( \pm)\end{array}$ & not studied \\
\hline $\begin{array}{l}\text { Ghosh et al. } \\
2015^{5}\end{array}$ & $\begin{array}{c}\text { mice, } \\
\text { cyclophosphamide } \\
\text { intraperitoneally } \\
25 \mathrm{mg} / \mathrm{kg} \text { b.w. } \\
10 \text { days or } 25 \text { days }\end{array}$ & $\begin{array}{c}\text { pulmonary ROS, NO, } \\
\text { lipid peroxidation } \uparrow ; \\
\text { GSH, GST, GPX, SOD, } \\
\text { CAT } \downarrow\end{array}$ & $\begin{array}{l}\text { a synthetic organic compound } \\
\text { 2-(5-selenocyanatopentyl)- } \\
\text { benzo[de)isoquinoline-1,3-dione } \\
3 \mathrm{mg} / \mathrm{kg} \text { b.w. (non-toxic dose), } \\
\text { oral gavage, } \\
2 \text { models: } \\
10 \text { days or } 25 \text { days; } 2 \text { models: } \\
\text { concomitant co-administration } \\
\text { of selenium } \\
\text { (10 days); } \\
\text { Se-pretreatment } \\
\text { (15 days before drug-exposure } \\
\text { and subsequent co-administration) }\end{array}$ & $\begin{array}{l}\text { oxidant parameters } \\
\text { considerably improved } \\
\text { by selenium; } \\
\text { the pretreatment model was } \\
\text { more effective, which was } \\
\text { confirmed by histopathological } \\
\text { studies of the lung: in co- } \\
\text { administered animals moderate } \\
\text { changes were observed, in the } \\
\text { pretreatment model no distinct } \\
\text { alterations were displayed } \\
\text { compared with control }\end{array}$ & none \\
\hline $\begin{array}{l}\text { Danesi et al. } \\
2006^{33}\end{array}$ & $\begin{array}{l}\text { rats } \\
\text { adriamycin, single } \\
\text { intraperitoneal dose } \\
10 \mathrm{mg} / \mathrm{kg} \text { b.w. }\end{array}$ & $\begin{array}{c}\text { plasma reactive oxygen } \\
\text { metabolites } \uparrow ; \\
\text { plasma total antioxidant } \\
\text { activity } \downarrow ; \\
\text { reactive oxygen } \\
\text { metabolites in heart } \uparrow\end{array}$ & $\begin{array}{c}\text { pretreatment with dietary } \mathrm{Na}_{2} \mathrm{SeO}_{3} \\
\text { or Se-enriched potato obtained } \\
\text { by foliar Se-supplementation } \\
\text { during growth } \\
0.1 \mathrm{mg} / \mathrm{kg} \\
60 \text { days }\end{array}$ & $\begin{array}{l}\text { plasma reactive oxygen } \\
\text { metabolites and total } \\
\text { antioxidant activity }(0) \text {; } \\
\text { heart reactive oxygen } \\
\text { metabolites: selenite }( \pm) \text {, } \\
\text { Se-enriched potato }(+)\end{array}$ & not studied \\
\hline $\begin{array}{c}\text { Saied and } \\
\text { Hamza } 2014^{34}\end{array}$ & $\begin{array}{c}\text { rats } \\
\text { isoretinoin } \\
\text { (a retinoid used } \\
\text { in dermatology) } \\
\text { gastric tube } \\
7.5 \mathrm{mg} / \mathrm{kg} \text { b.w. } \\
28 \text { days }\end{array}$ & $\begin{array}{c}\text { ALT, AST, ALP, total } \\
\text { cholesterol and } \\
\text { triglycerides, TBARS } \uparrow ; \\
\text { HDL, GSH, SOD, CAT } \downarrow\end{array}$ & $\begin{array}{c}\mathrm{Na}_{2} \mathrm{SeO}_{3} \\
500 \mu \mathrm{g} / \mathrm{kg} / \text { day, gastric tube, } \\
28 \text { days }\end{array}$ & $\begin{array}{c}\text { ALT, ALP, TBARS, total } \\
\text { cholesterol, triglycerides }( \pm) \text {; } \\
\text { SOD, CAT }(0) ; \\
\text { AST, HDL, GSH (+) }\end{array}$ & $\begin{array}{l}\text { SOD, CAT, } \\
\text { HDL } \uparrow\end{array}$ \\
\hline $\begin{array}{l}\text { Mossa et al. } \\
2014^{35}\end{array}$ & $\begin{array}{c}\text { rats } \\
\text { aspirin } \\
22.5 \mathrm{mg} / \mathrm{kg} \mathrm{b.w} \text {. } \\
28 \text { days }\end{array}$ & $\begin{array}{c}\text { erythrocytes SOD, CAT, } \\
\text { GPx } \downarrow ; \\
\text { erythrocytes MDA } \uparrow\end{array}$ & $\begin{array}{c}\mathrm{Na}_{2} \mathrm{SeO}_{3} \\
200 \mu \mathrm{g} / \mathrm{kg} \mathrm{b.w./day,} \mathrm{orally} \\
28 \text { days }\end{array}$ & $\begin{array}{c}\text { erythrocytes SOD, CAT, GPx, } \\
\text { MDA (+) }\end{array}$ & none \\
\hline
\end{tabular}

$\downarrow$ - decrease; $\uparrow$ - increase; (+) - full protection; $( \pm$ ) - partial protection; (0) - lack of protection. GSH - reduced glutathione; ROS - reactive oxygen species; NO - nitrogen oxide; GST - glutathione S-transferase; GPX - glutathione peroxidase; SOD - superoxide dismutase; CAT - catalase; ALP - alkaline phosphatase; AST - aspartate aminotransferase; ALT - alanine aminotransferase; HDL - high-density lipoproteins.

that the organic forms are more beneficial and less likely to induce their own toxic effects. In mice treated with either sodium selenite or naphthalimide-based synthetic organoselenocyanates (oral gavage; $1.2 \mathrm{mg} / \mathrm{kg}$ b.w. and $3 \mathrm{mg} / \mathrm{kg}$ b.w., respectively), selenite significantly decreased hemoglobin as well as increased aspartate aminotransferase (AST), alanine aminotransferase (ALT), and hepatic lipid peroxidation. Organic selenium depressed AST and ALT as well as blood urea nitrogen and creatinine, indicating the potential hepatoprotective and nephroprotective effects of this form. Histopathological studies have confirmed these outcomes. The advantage of the organic form was also observed in the case of liver antioxidant parameters. ${ }^{24}$

In one of the newest studies, sodium selenite, selenomethionine and selenium yeast were compared in vitro $(1 \mu \mathrm{g} / \mathrm{mL}$ in cell medium). In HepG2 cells exposed to lead nitrate ( $40 \mu \mathrm{g}$ of $\mathrm{Pb} / \mathrm{mL}$ or $80 \mu \mathrm{g}$ of $\mathrm{Pb} / \mathrm{mL}$ ), DNA damage was reduced by organic selenium, whereas selenite not only was ineffective as a protective agent, but also intensified DNA injury. ${ }^{6}$

Four dietary selenium forms (selenite, lactate-protein complex, Se-proteinate, and Se-yeast), given to goats before $(0.3 \mathrm{mg} /$ day/goat $)$ and after parturition $(0.9 \mathrm{mg} /$ day/goat $)$, were studied as potential Se-supplements. Tissue selenium content in different organs of the younglings were the highest in the Se-yeast group, but the other organic forms were also more effective as supplements than selenite. ${ }^{27}$

Sodium selenite was also compared with dextrin stabilized selenium nanoparticles (both forms used at doses $10-100 \mu \mathrm{g} / \mathrm{mL}$ ). An in vitro investigation revealed that the viability of the nanoparticle-treated cells was much higher than in the case of those treated by selenite. In an in vivo 
Table 3. Protective effect of selenium against cadmium toxicity

\begin{tabular}{|c|c|c|c|c|c|}
\hline $\begin{array}{l}\text { Authors, } \\
\text { citation } \\
\text { number }\end{array}$ & $\begin{array}{c}\text { Animals, } \\
\text { way of } \\
\text { administration, } \\
\text { dose, } \\
\text { time of exposure }\end{array}$ & $\begin{array}{l}\text { Cadmium-induced } \\
\text { harmful effects }\end{array}$ & $\begin{array}{l}\text { Selenium form, } \\
\text { dose, } \\
\text { method and time } \\
\text { of administration }\end{array}$ & $\begin{array}{l}\text { Effects of selenium } \\
\text { co-administration }\end{array}$ & $\begin{array}{l}\text { Effects } \\
\text { of Se itself }\end{array}$ \\
\hline Li et al. $2013^{14}$ & $\begin{array}{l}\text { chickens } \\
\mathrm{CdCl}_{2} \\
150 \mathrm{mg} / \mathrm{kg} \text { of diet } \\
60 \text { days }\end{array}$ & $\begin{array}{l}\text { liver lipid peroxidation, } \\
\text { NO level and nitric oxide } \\
\text { synthase activity } \uparrow ; \\
\text { liver SOD, GPx } \downarrow \text {; } \\
\text { the number of apoptotic } \\
\text { cells } \uparrow\end{array}$ & $\begin{array}{c}\text { dietary } \mathrm{Na}_{2} \mathrm{SeO}_{3} \\
10 \mathrm{mg} / \mathrm{kg} \\
60 \text { days }\end{array}$ & $\begin{array}{l}\text { liver lipid peroxidation, NO level, } \\
\text { nitric oxide synthase activity, } \\
\text { SOD, GPx }( \pm) \text {; } \\
\text { the number of apoptotic cells }( \pm)\end{array}$ & $\mathrm{GPx} \uparrow$ \\
\hline $\begin{array}{l}\text { El-Boshy et al. } \\
2015^{37}\end{array}$ & $\begin{array}{c}\text { rats } \\
\text { cadmium } \\
40 \mathrm{mg} / \mathrm{L} \text { in drinking } \\
\text { water as } \mathrm{CdCl}_{2} \\
30 \text { days }\end{array}$ & $\begin{array}{c}\text { serum tumor necrosis } \\
\text { factor } \alpha \text {, interleukins IL-6, } \\
\text { IL-10, IL- } \beta, \text { MDA } \uparrow ; \\
\text { serum interferon } \gamma \text {, GSH, } \\
\text { GPx, CAT, SOD } \downarrow ; \\
\text { ALT and AST, urea and } \\
\text { creatinine } \uparrow\end{array}$ & $\begin{array}{c}\mathrm{Na}_{2} \mathrm{SeO}_{3} \\
0.1 \mathrm{mg} / \mathrm{kg} \text { b.w., orally }\end{array}$ & $\begin{array}{l}\text { serum tumor necrosis factor } \alpha \text {, } \\
\text { IL-6, IL-10, interferon } \gamma, \text { MDA, GSH, } \\
\text { GPx, CAT, SOD, ALT, AST, urea and } \\
\text { creatinine }(+) ; \\
\text { IL- } \beta(0)\end{array}$ & $\begin{array}{l}\text { serum } \\
\text { interferon } \\
\text { Y (IFN- }- \text { ), } \\
\text { GSH, GPX, } \\
\text { CAT } \uparrow ; \\
\text { IL-10 } \downarrow\end{array}$ \\
\hline $\begin{array}{c}\text { Sk and } \\
\text { Bhattacharya } \\
2006^{26}\end{array}$ & $\begin{array}{l}\text { mice } \\
\mathrm{CdCl}_{2} \\
\text { intraperitoneally } \\
1 \text { or } 2 \mathrm{mg} / \mathrm{kg} \text { b.w. } \\
20 \text { days }\end{array}$ & $\begin{array}{c}\text { serum ALT and AST, } \\
\text { hepatic microsomal lipid } \\
\text { peroxidation } \uparrow \text {; } \\
\text { liver cytosol GST, SOD, CAT, } \\
\text { GSH } \downarrow\end{array}$ & $\begin{array}{l}\text { synthetic selenocyanates } \\
3 \mathrm{mg} / \mathrm{kg} \text { b.w., by gavage } \\
2 \text { models: } \\
\text { concomitant; } \\
\text { pretreatment } \\
\text { (selenium given } 7 \text { days before } \\
\text { cadmium, and then throughout } \\
\text { the experimental period of } \\
20 \text { days) }\end{array}$ & $\begin{array}{c}\text { serum ALT and AST, hepatic } \\
\text { microsomal lipid peroxidation, } \\
\text { liver cytosol GST, SOD, CAT, GSH } \\
( \pm) \text {; } \\
\text { pretreatment model more } \\
\text { effective }\end{array}$ & not studied \\
\hline $\begin{array}{l}\text { Vargas et al. } \\
2013^{17}\end{array}$ & $\begin{array}{c}\text { mice } \\
\mathrm{CdCl}_{2} \text {, single } \\
\text { intraperitoneal } \\
\text { dose }\end{array}$ & $\begin{array}{l}\text { ovary } \delta \text {-aminolevulinate } \\
\text { dehydratase activity } \downarrow\end{array}$ & $\begin{array}{c}\text { synthetic } \\
\text { seleno-furanoside } \\
100 \mu \mathrm{mol}(32.9 \mathrm{mg}) / \mathrm{kg} \\
\text { subcutaneously }\end{array}$ & $\begin{array}{l}\text { in } \mathrm{CdCl}_{2} 2.5 \mathrm{mg} / \mathrm{kg} \text { group }( \pm) \\
\text { in } \mathrm{CdCl}_{2} 5 \mathrm{mg} / \mathrm{kg} \text { group }(+)\end{array}$ & none \\
\hline
\end{tabular}

$\downarrow$ - decrease; $\uparrow$ - increase; $(+)$ - full protection; $( \pm$ ) - partial protection; (0) - lack of protection. NO - nitrogen oxide; SOD - superoxide dismutase; GPX glutathione peroxidase; MDA - malonyldialdehyde; GSH - reduced glutathione; CAT - catalase; ALT - alanine aminotransferase;

AST - aspartate aminotransferase; GST - glutathione S-transferase.

study, rats with arthritis showed depletion of superoxide dismutase (SOD), catalase (CAT) and glutathione peroxidase (GPx) in the liver, kidney and spleen as well as an increase in serum C-reactive protein. These disturbances were reversed by oral administration of nanoparticles $(100 \mu \mathrm{g} / \mathrm{kg}$ b.w., $250 \mu \mathrm{g} / \mathrm{kg}$ b.w., $500 \mu \mathrm{g} / \mathrm{kg}$ b.w., or $750 \mu \mathrm{g} / \mathrm{kg}$ b.w.). ${ }^{28}$ On the other hand, treatment with selenium nanoparticles (5-25 $\mu \mathrm{g} / \mathrm{mL})$ was reported to cause dose-dependent malformations in zebrafish embryos, whereas the same doses of sodium selenite did not show any harmful effects. ${ }^{29}$

A comparison of Se-enriched probiotics and sodium selenite was performed on rats exposed to carbon tetrachloride. $\mathrm{CCl}_{4}$ significantly increased serum ALT and AST, and disturbed liver oxidant balance. Both selenium forms alleviated the harmful effects, but the Se-enriched probiotics were more effective. ${ }^{3}$

\section{Protecting effect of selenium against toxicity of different substances}

\section{Protective properties of selenium against toxicity of diverse drugs: Animal model research}

Administration of drugs can be connected with side effects causing the impairment of organism functions. Selenium was found to protect against the toxicity of different drugs, including the chemotherapeutic agents - cisplatin and cyclophosphamide, antibiotics and dermatological medications as well as aspirin. The research also showed the pretreatment application to be more effective. The details of the studies performed and their results are presented in Tables 1 and 2. 
Table 4. Protective effect of organic selenium against toxicity of aluminum, mercury and arsenic

\begin{tabular}{|c|c|c|c|c|c|}
\hline $\begin{array}{l}\text { Authors, } \\
\text { citation } \\
\text { number }\end{array}$ & $\begin{array}{c}\text { Animals, } \\
\text { way of administartion, } \\
\text { dose, } \\
\text { time of exposure }\end{array}$ & $\begin{array}{l}\text { Induced harmful } \\
\text { effects }\end{array}$ & $\begin{array}{l}\text { Selenium form, } \\
\text { dose, } \\
\text { method and time } \\
\text { of administration }\end{array}$ & $\begin{array}{l}\text { Effects of selenium } \\
\text { co-administration }\end{array}$ & $\begin{array}{c}\text { Effects } \\
\text { of Se itself }\end{array}$ \\
\hline $\begin{array}{l}\text { Viezeliene } \\
\text { et al. } 2013^{38}\end{array}$ & $\begin{array}{c}\text { mice } \\
\mathrm{AlCl}_{3} \text {, intraperitoneally } \\
25 \mathrm{mg} \mathrm{Al}{ }^{3+} / \mathrm{kg} \text { b.w. } \\
16 \mathrm{~h}\end{array}$ & $\begin{array}{c}\text { serum interleukin IL-6 } \uparrow \text {; } \\
\text { liver total GSH } \downarrow\end{array}$ & $\begin{array}{c}\mathrm{Na}_{2} \mathrm{SeO}_{3,} \\
1.25 \mathrm{mg} \text { of } \mathrm{Se}^{4+} / \mathrm{kg} \text { b.w., } \\
\text { intraperitoneally } \\
16 \mathrm{~h}\end{array}$ & $\begin{array}{l}\qquad \mathrm{IL}-6( \pm) ; \\
\text { liver total GSH (+) }\end{array}$ & $\begin{array}{l}\text { liver total } \\
\text { GSH } \uparrow ; \\
\text { serum } \\
\text { IL-6 } \uparrow\end{array}$ \\
\hline $\begin{array}{l}\text { Lakshmi et al. } \\
\qquad 2015^{39}\end{array}$ & $\begin{array}{c}\text { rats } \\
\mathrm{AlCl}_{3} \\
100 \mathrm{mg} / \mathrm{kg} \text {, orally }\end{array}$ & $\begin{array}{c}\text { brain CAT, GSH, GR, } \\
\text { AChE } \downarrow ; \\
\text { MDA } \uparrow\end{array}$ & $\begin{array}{c}\text { selenium } \\
1 \mathrm{mg} / \mathrm{kg} \text {, orally }\end{array}$ & $\begin{array}{l}\text { brain CAT, AChE }( \pm) \\
\text { GSH, GR, MDA }(+)\end{array}$ & $\begin{array}{l}\text { brain GSH, } \\
\text { GR } \uparrow ; \\
\text { MDA } \downarrow\end{array}$ \\
\hline $\begin{array}{l}\text { Agarwal and } \\
\text { Behari } 2007^{1}\end{array}$ & $\begin{array}{c}\text { rats } \\
\text { mercuric chloride, } \\
\text { intraperitoneally } \\
0.4 \mathrm{mg} / \mathrm{kg} / \text { day } \\
20 \text { days }\end{array}$ & $\begin{array}{c}\text { brain, liver and kidney } \\
\text { lipid peroxidation } \uparrow ; \\
\text { brain, liver and kidney } \\
\text { GSH } \downarrow \text {; } \\
\text { brain, liver and kidney } \\
\text { Hg concentration } \uparrow\end{array}$ & $\begin{array}{c}\mathrm{Na}_{2} \mathrm{SeO}_{3} \\
0.2 \mathrm{mg} / \mathrm{kg} / \mathrm{day} \text {, intraperitoneally } \\
4 \mathrm{~h} \text { before mercury, } 20 \text { days }\end{array}$ & $\begin{array}{c}\text { brain, liver and kidney lipid } \\
\text { peroxidation and GSH, } \\
\text { brain } \mathrm{Hg}(0) ; \\
\text { liver and kidney } \mathrm{Hg} \\
\text { concentration (-) }\end{array}$ & $\begin{array}{l}\text { liver MDA } \uparrow \text {; } \\
\text { kidney } \\
\text { GSH } \downarrow\end{array}$ \\
\hline $\begin{array}{l}\text { Glaser et al. } \\
2013^{19}\end{array}$ & $\begin{array}{c}\text { mice } \\
\text { methylmercury } \\
\text { (MeHg), orally } \\
\text { in drinking water } \\
40 \mathrm{mg} / \mathrm{L} \\
21 \text { days }\end{array}$ & $\begin{array}{c}\text { GPx, respiratory chain } \\
\text { enzymes } \\
\text { in cortical mitochondrial } \\
\text { preparations } \downarrow ; \\
\text { GR, TBARS in cortical } \\
\text { mitochondrial } \\
\text { preparations } \uparrow ; \\
\text { cerebral cortex } \mathrm{Hg} \\
\text { deposition } \uparrow\end{array}$ & $\begin{array}{c}\text { diphenyl diselenide } \\
5 \mu \mathrm{mol} / \mathrm{kg} \text {, subcutaneously } \\
21 \text { days }\end{array}$ & $\begin{array}{l}\text { TBARS, respiratory chain } \\
\text { enzymes in cortical } \\
\text { mitochondrial preparations }(+) \text {; } \\
\text { GPx, GR in cortical } \\
\text { mitochondrial preparations }(0) \text {; } \\
\text { cerebral cortex Hg deposition } \\
( \pm)\end{array}$ & $\begin{array}{c}\text { GR } \uparrow ; \\
\text { TBARS } \downarrow ; \\
\text { cerebral } \\
\text { cortex Hg } \\
\text { deposition } \\
\uparrow\end{array}$ \\
\hline $\begin{array}{l}\text { Prasad and } \\
\text { Selvaraj } 2014^{40}\end{array}$ & $\begin{array}{c}\text { human lymphocytes } \\
\text { sodium arsenite } \\
\mathrm{NaAsO}_{2} \\
10 \mu \mathrm{M} \\
1 \mathrm{~h}\end{array}$ & $\begin{array}{l}\text { increased cell death; } \\
\text { DNA damage }\end{array}$ & $\begin{array}{c}\text { selenium nanoparticles } \\
0.01 \mu \mathrm{g} / \mu \mathrm{L} \\
1 \mathrm{~h}\end{array}$ & $\begin{array}{l}\text { protecting from DNA damage } \\
\text { and cell death }\end{array}$ & not studied \\
\hline Xu et al. $2013^{41}$ & $\begin{array}{c}\text { rats } \\
\text { sodium arsenite } \\
\mathrm{NaAsO}_{2} \text {, in drinking } \\
\text { water } \\
13 \mathrm{mg} / \mathrm{L} \\
20 \text { weeks }\end{array}$ & $\begin{array}{l}\text { liver MDA } \uparrow ; \\
\text { liver CAT, GPX, SOD } \downarrow ; \\
\text { serum ALT and AST } \uparrow\end{array}$ & $\begin{array}{c}\mathrm{Na}_{2} \mathrm{SeO}_{3} \\
17.0 \mathrm{mg} / \mathrm{L}, \text { in drinking water } \\
20 \text { weeks }\end{array}$ & $\begin{array}{l}\text { liver MDA }(+) ; \\
\text { liver CAT, GPx, SOD }( \pm) \\
\text { serum ALT and AST }(+)\end{array}$ & liver CAT $\downarrow$ \\
\hline
\end{tabular}

$\downarrow$ - decrease; $\uparrow$ - increase; (+) - full protection; ( \pm ) - partial protection; (0) - lack of protection; (-) - intensification of harmful effects. GSH - reduced glutathione; CAT - catalase; GR - glutathione reductase; AChE - acetylcholinesterase; MDA - malonyldialdehyde; GPx - glutathione peroxidase; TBARS thiobarbituric acid-reactive substances; SOD - superoxide dismutase; ALT - alanine aminotransferase; AST - aspartate aminotransferase.

\section{Protective properties of selenium against environmental contaminants and physical factors: Animal model research}

Selenium has been studied in regard to its possible protective effect against numerous environmental pollutants, and the results obtained seem to be very promising. The harmful effects of toxic elements (cadmium, aluminum, mercury, arsenic, lead, chromium) and compounds, e.g., carbon tetrachloride, carcinogens (acrylamide, hydrocarbons), mycotoxins (patulin, aflatoxin), and pesticides (beta-cyfluthrin), diazinon, acephate) were found to be reversed or alleviated by selenium treatment. Sodium selenite was most often used, but organic forms were also studied. Some researchers applied very interesting, new natural forms like polysaccharides isolated from selenium-enriched Ziyang tea, or meat from lambs receiving Se-nanoparticles in drinking water. ${ }^{7,10}$ Synthetic organoselenium compounds also revealed their advantage over inorganic forms. Diphenyl diselenide was proved effective against the toxicity of mercury in rodents, while selenite showed no efficacy. ${ }^{1,19}$ It was also found that the influence of selenium was dependent on its dose. ${ }^{10,36}$ The detailed information is collected in Tables 3-8.

\section{In vitro studies of protective properties of selenium}

The beneficial impact of different forms of selenium against the toxicity of diverse factors has also been confirmed by in vitro studies.

In neuronal cells exposed to the addictive drug methamphetamine, a decrease in GPx isoforms (GPx 1 and GPx 4), and the depletion of GPx activity and intracellular reduced glutathione (GSH) was observed. However, in cells cultured in Se-containing media ( $10 \mathrm{nM}$ or $100 \mathrm{nM}$ as sodium selenite), before and during methamphetamine exposure, these effects were alleviated, although in the case of GPx 
Table 5. Protective effect of selenium against toxicity of lead and chromium

\begin{tabular}{|c|c|c|c|c|c|}
\hline $\begin{array}{l}\text { Authors, } \\
\text { citation } \\
\text { number }\end{array}$ & $\begin{array}{c}\text { Animals, } \\
\text { way of administration, } \\
\text { dose, } \\
\text { time of exposure }\end{array}$ & Induced harmful effects & $\begin{array}{l}\text { Selenium form, } \\
\text { dose, } \\
\text { method and time } \\
\text { of administration }\end{array}$ & $\begin{array}{l}\text { Effects of selenium } \\
\text { co-administration }\end{array}$ & $\begin{array}{l}\text { Effects of } \\
\text { Se itself }\end{array}$ \\
\hline $\begin{array}{l}\text { Han et al. } \\
2014^{8}\end{array}$ & $\begin{array}{l}\text { weaned rats } \\
\mathrm{PbCl}_{2} \text {, in drinking water } \\
2 \mathrm{mmol} / \mathrm{L} \\
3 \text { weeks }\end{array}$ & $\begin{array}{l}\text { deteriorations of synaptic } \\
\text { structural plasticity as well as } \\
\text { impaired spatial learning and } \\
\text { memory }\end{array}$ & $\begin{array}{l}\text { Se-enriched yeast } \\
6 \mu \mathrm{g} / 100 \mathrm{~g} \text { b.w., by } \\
\text { gavage } \\
3 \text { weeks after } \mathrm{Pb} \\
\text { exposure }\end{array}$ & $\begin{array}{l}\text { Pb-induced effects were } \\
\text { improved by the subsequent } \\
\text { treatment with selenium }\end{array}$ & not studied \\
\hline $\begin{array}{l}\text { Baş et al. } \\
2015^{42}\end{array}$ & $\begin{array}{c}\text { rats } \\
\text { lead nitrate, by gavage } \\
22.5 \mathrm{mg} / \mathrm{kg} \text { b.w. } \\
\left(1 / 100 \mathrm{LD}_{50}\right) \\
28 \text { days }\end{array}$ & $\begin{array}{c}\text { MDA in erythrocytes and } \\
\text { leucocytes } \uparrow ; \\
\text { SOD, CAT, GPx, GST } \\
\text { in erythrocytes and leucocytes } \downarrow ; \\
\text { plasma antioxidant capacity } \downarrow\end{array}$ & $\begin{array}{c}\mathrm{Na}_{2} \mathrm{SeO}_{3} \\
1 \mathrm{mg} / \mathrm{kg} \mathrm{b.W.,} \mathrm{by} \mathrm{gavage} \\
28 \text { days }\end{array}$ & $\begin{array}{c}\text { MDA, SOD, CAT, GPx, GST } \\
\text { in erythrocytes and leucocytes }( \pm) \\
\text { plasma antioxidant capacity }( \pm)\end{array}$ & none \\
\hline $\begin{array}{l}\text { Soudani et al. } \\
\qquad 2011^{43}\end{array}$ & $\begin{array}{c}\text { rats } \\
\mathrm{K}_{2} \mathrm{Cr}_{2} \mathrm{O}_{7} \text {, in drinking } \\
\text { water } \\
700 \text { ppm } \\
3 \text { weeks }\end{array}$ & $\begin{array}{c}\text { heart SOD, CAT, GPx, MDA } \uparrow \text {; } \\
\text { heart GSH, vitamin C, non- } \\
\text { protein thiols, LDH activity } \downarrow ; \\
\text { plasma LDL, ALT, AST, bilirubin, } \\
\text { total cholesterol, triglycerides, } \\
\text { LDL-cholesterol } \uparrow ; \\
\text { plasma HDL-cholesterol } \downarrow\end{array}$ & $\begin{array}{c}\text { dietary } \mathrm{Na}_{2} \mathrm{SeO}_{3} \\
0.5 \mathrm{mg} / \mathrm{kg} \\
3 \text { weeks }\end{array}$ & $\begin{array}{c}\text { heart SOD, CAT, GPx, MDA, } \\
\text { vitamin C, non-protein thiols, } \\
\text { LDH }( \pm) \text {; } \\
\text { heart GSH, plasma ALT, AST, } \\
\text { total cholesterol, HDL- } \\
\text { cholesterol, LDL-cholesterol, } \\
\text { triglycerides }(+) ; \\
\text { plasma bilirubin }( \pm)\end{array}$ & $\begin{array}{l}\text { heart non- } \\
\text { protein } \\
\text { thiols } \uparrow ; \\
\text { heart SOD } \\
\quad \downarrow\end{array}$ \\
\hline $\begin{array}{l}\text { Soudani et al. } \\
2012^{44}\end{array}$ & $\begin{array}{c}\text { rats } \\
\mathrm{K}_{2} \mathrm{Cr}_{2} \mathrm{O}_{7} \text {, in drinking } \\
\text { water } \\
700 \text { ppm } \\
3 \text { weeks }\end{array}$ & $\begin{array}{c}\text { cerebrum and cerebellum } \\
\text { MDA, SOD, GPx, CAT, } \\
\text { plasma LDH } \uparrow ; \\
\text { cerebrum and cerebellum GSH, } \\
\text { non-protein thiols, vitamin C, } \\
\text { AChE, LDH } \downarrow\end{array}$ & $\begin{array}{c}\text { dietary } \mathrm{Na}_{2} \mathrm{SeO}_{3} \\
0.5 \mathrm{mg} / \mathrm{kg} \\
3 \text { weeks }\end{array}$ & $\begin{array}{c}\text { cerebrum and cerebellum MDA, } \\
\text { SOD, GSH, non-protein thiols, } \\
\text { vitamin C, GPX, LDH, AChE, } \\
\text { cerebrum CAT }( \pm) \\
\text { cerebellum CAT }(0) \\
\text { plasma LDH }(+)\end{array}$ & $\begin{array}{l}\text { cerebrum } \\
\text { non-protein } \\
\text { thiols } \uparrow\end{array}$ \\
\hline $\begin{array}{l}\text { Hassanin et al. } \\
2013^{18}\end{array}$ & $\begin{array}{c}\text { rats } \\
\mathrm{K}_{2} \mathrm{Cr}_{2} \mathrm{O}_{7} \text {, single } \\
\text { intraperitoneal dose } \\
60 \mu \mathrm{g} / \mathrm{kg} \text { b.w. } \\
\text { in } \mathrm{Cr}+\text { Se animals, } \\
\text { Cr was given on day } 3\end{array}$ & $\begin{array}{l}\text { serum thyroid hormones } \\
\text { (free triiodothyronine and } \\
\text { thyroxine), GSH } \downarrow \text {; } \\
\text { serum CAT, SOD and MDA } \uparrow ; \\
\text { in thyroid: hyperplasia of } \\
\text { intrafollicular epithelium, } \\
\text { follicular segregation, increased } \\
\text { interfollicular spaces, increased } \\
\text { collagen deposition }\end{array}$ & $\begin{array}{c}\text { selenium nanoparticles, } \\
\text { intraperitoneally } \\
0.5 \mathrm{mg} / \mathrm{kg} \text { b.w. } \\
5 \text { days }\end{array}$ & $\begin{array}{c}\text { serum thyroid hormones (free } \\
\text { triiodothyronine and thyroxine) } \\
\qquad( \pm)_{i} \\
\text { serum GSH, CAT, SOD } \\
\text { and MDA }(+) ; \\
\text { alleviated histopathological } \\
\text { changes }\end{array}$ & none \\
\hline
\end{tabular}

$\downarrow$ - decrease; $\uparrow$ - increase; (+) - full protection; $( \pm$ ) - partial protection; (0) - lack of protection; MDA - malonyldialdehyde; SOD - superoxide dismutase; CAT - catalase; GPx - glutathione peroxidase; GST - glutathione S-transferase; GSH - reduced glutathione; LDH - lactate dehydrogenase; LDL - low-density lipoproteins; ALT - alanine aminotransferase; AST - aspartate aminotransferase; AChE - acetylcholinesterase.

Table 6. Protective effect of organic selenium against toxicity of carbon tetrachloride and other carcinogens

\begin{tabular}{|c|c|c|c|c|c|}
\hline $\begin{array}{l}\text { Authors, } \\
\text { citation } \\
\text { number }\end{array}$ & $\begin{array}{c}\text { Animals, } \\
\text { way of administration, } \\
\text { dose, } \\
\text { time of exposure }\end{array}$ & $\begin{array}{l}\text { Induced harmful } \\
\text { effects }\end{array}$ & $\begin{array}{l}\text { Selenium form, } \\
\text { dose, } \\
\text { method and time } \\
\text { of administration }\end{array}$ & $\begin{array}{l}\text { Effects of selenium } \\
\text { co-administration }\end{array}$ & $\begin{array}{l}\text { Effects of } \\
\text { Se itself }\end{array}$ \\
\hline $\begin{array}{l}\text { Ding et al. } \\
2010^{45}\end{array}$ & $\begin{array}{c}\text { mice } \\
\mathrm{CCl}_{4} \text {, intraperitoneally } \\
5 \mu \mathrm{L} \text { of a } 20 \% \text { solution } \\
\text { in olive oil } \\
\text { biweekly for } 4 \text { weeks }\end{array}$ & $\begin{array}{l}\text { liver GPx } \downarrow ; \\
\text { liver MDA, serum ALT, } \\
\text { liver fibrosis, liver } \alpha_{1}(I) \\
\text { collagen mRNA } \uparrow\end{array}$ & $\begin{array}{c}\mathrm{Na}_{2} \mathrm{SeO}_{3} \\
4 \mathrm{mg} / \mathrm{L} \text {, in drinking water } \\
\text { started } 2 \text { days before } \mathrm{CCl}_{4}\end{array}$ & $\begin{array}{c}\text { liver GPx and MDA (+); } \\
\text { liver fibrosis }( \pm) ; \\
\text { serum ALT, liver } \alpha_{1}(\mathrm{I}) \text { collagen } \\
\text { mRNA }(0)\end{array}$ & $\begin{array}{l}\text { liver GPx } \uparrow ; \\
\text { liver MDA } \downarrow\end{array}$ \\
\hline $\begin{array}{l}\text { Wang et al. } \\
2014^{10}\end{array}$ & $\begin{array}{c}\text { mice } \\
\mathrm{CCl}_{4} \text {, intraperitoneally } \\
0.3 \mu \mathrm{L} \text { of a } 0.8 \% \\
\text { solution in peanut oil } \\
\text { once }\end{array}$ & $\begin{array}{c}\text { serum ALT, AST } \\
\text { and LDH } \uparrow ; \\
\text { liver MDA } \uparrow ; \\
\text { liver SOD and GPx } \downarrow\end{array}$ & $\begin{array}{l}\text { polysaccharides isolated from } \\
\text { selenium-enriched Ziyang tea } \\
\text { 100, } 200 \text { and } 400 \mathrm{mg} / \mathrm{kg} \text { b.w. } \\
\text { intragastrically } \\
\text { daily for } 14 \text { days before } \mathrm{CCl}_{4}\end{array}$ & $\begin{array}{l}\text { serum ALT, AST and LDH }( \pm) \\
\text { liver MDA, SOD: Iow dose }(0) \text {, } \\
\text { middle and high doses }( \pm) \\
\text { liver GPX: all doses }( \pm)\end{array}$ & not studied \\
\hline $\begin{array}{l}\text { Ali et al. } \\
2014^{46}\end{array}$ & $\begin{array}{c}\text { rats } \\
\text { acrylamide, gastric } \\
\text { intubation } \\
15 \mathrm{mg} / \mathrm{kg} \text { b.w./day } \\
28 \text { days }\end{array}$ & $\begin{array}{c}\text { erythrocytes, leucocytes } \\
\text { and hematocrit, serum } \\
\text { Zn and ALP } \downarrow ; \\
\text { MDA, Na, Ca in retinas } \uparrow ; \\
\text { retinas GPx and K } \downarrow\end{array}$ & $\begin{array}{l}0.1 \mathrm{mg} / \mathrm{kg} \text { b.w./day, } \\
\text { gastric intubation } \\
\text { for } 28 \text { days }\end{array}$ & all studied parameters (+) & none \\
\hline $\begin{array}{l}\text { Ungvári et al. } \\
\qquad 2014^{7}\end{array}$ & $\begin{array}{c}\text { mice } \\
\text { hydrocarbon DMBA, } \\
\text { 7,12-dimethyl-bez(a) } \\
\text { antracene, single } \\
\text { intraperitoneal dose } \\
200 \mathrm{mg} / \mathrm{kg} \text { b.w. }\end{array}$ & $\begin{array}{l}\text { blood total antioxidant } \\
\text { capacity, total white } \\
\text { blood cells counts } \downarrow \text {; } \\
\text { impaired granulopoiesis }\end{array}$ & $\begin{array}{l}\text { meat from lambs receiving } \\
\text { selenium nanoparticles in } \\
\text { drinking water }(0.1 \%)\end{array}$ & $\begin{array}{l}\text { blood total antioxidant capacity } \\
\qquad(+) ; \\
\text { total white blood cells counts } \\
( \pm) ; \\
\text { granulopoiesis }( \pm)\end{array}$ & $\begin{array}{c}\text { blood total } \\
\text { antioxidant } \\
\text { capacity } \uparrow ; \\
\text { intensified } \\
\text { granulo- } \\
\text { poiesis }\end{array}$ \\
\hline
\end{tabular}

$\downarrow$ - decrease; $\uparrow$ - increase; (+) - full protection; $( \pm$ ) - partial protection; (0) - lack of protection; DMBA - 7,12-dimethylbenz(a)anthracene; GPx - glutathione peroxidase; MDA - malonyldialdehyde; ALT - alanine aminotransferase; AST - aspartate aminotransferase; LDH - lactate dehydrogenase; SOD - superoxide dismutase; ALP - alkaline phosphatase. 
Table 7. Protective effect of organic selenium against toxicity of mycotoxins and substances used in agriculture

\begin{tabular}{|c|c|c|c|c|c|}
\hline $\begin{array}{l}\text { Authors, } \\
\text { citation } \\
\text { number }\end{array}$ & $\begin{array}{c}\text { Animals, } \\
\text { way of } \\
\text { administration, } \\
\text { dose, } \\
\text { time of exposure }\end{array}$ & $\begin{array}{l}\text { Induced harmful } \\
\text { effects }\end{array}$ & $\begin{array}{l}\text { Selenium form, } \\
\text { dose, } \\
\text { method and time } \\
\text { of administration }\end{array}$ & $\begin{array}{l}\text { Effects of selenium } \\
\text { co-administration }\end{array}$ & $\begin{array}{l}\text { Effects of } \\
\text { Se itself }\end{array}$ \\
\hline $\begin{array}{l}\text { Song et al. } \\
2014^{22}\end{array}$ & $\begin{array}{c}\text { mice } \\
\text { patulin } \\
\text { intraperitoneally } \\
1 \mathrm{mg} / \mathrm{kg} \\
\text { once a week } \\
\text { for } 8 \text { weeks }\end{array}$ & $\begin{array}{l}\text { brain thiol group, } \\
\text { GPx, GR, TrxR } \\
\text { mRNA expressions } \downarrow \text {; } \\
\text { brain oxidized } \\
\text { glutathione, ROS } \\
\text { generation, TBARS, } \\
\text { protein carbonyls } \uparrow\end{array}$ & $\begin{array}{c}\text { dietary } \mathrm{Na}_{2} \mathrm{SeO}_{3} \\
\text { or selenomethionine } \\
0.2 \mathrm{mg} \mathrm{Se} / \mathrm{kg}\end{array}$ & all studied parameters (+) & not studied \\
\hline $\begin{array}{l}\text { Liao et al. } \\
2014^{47}\end{array}$ & $\begin{array}{c}\text { ducklings } \\
\text { aflatoxin } B_{1} \\
\text { intragastrically } \\
0.1 \mathrm{mg} / \mathrm{kg} \text { b.w. } \\
14,21 \text {, and } 28 \text { days }\end{array}$ & $\begin{array}{c}\text { serum ALT and AST个; } \\
\text { liver Bax and caspase-3 } \uparrow ; \\
\text { liver Bcl-2 } \downarrow\end{array}$ & $\begin{array}{c}\mathrm{Na}_{2} \mathrm{SeO}_{3} \\
1 \mathrm{mg} \text { of Se/kg b.w., } \\
\text { intragastically, } \\
5 \text { min after aflatoxin } \\
\text { for } 14,21 \text {, and } 28 \text { days }\end{array}$ & $\begin{array}{l}\text { serum ALT and AST(+); } \\
\text { liver caspase-3 }(+) ; \\
\text { liver } \mathrm{BCl}-2 \text { and } \mathrm{Bax}( \pm)\end{array}$ & not studied \\
\hline $\begin{array}{l}\text { Chen et al. } \\
2013^{36}\end{array}$ & $\begin{array}{c}\text { broilers } \\
\text { aflatoxin } \mathrm{B}_{1} \text {, in diet } \\
0.3 \mathrm{mg} / \mathrm{kg} \\
7,14 \text {, and } 21 \text { days }\end{array}$ & $\begin{array}{c}\text { peripheral blood } \\
\text { T-cell subsets, serum } \\
\text { interleukin IL-2 and } \\
\text { interferon- } \gamma(\text { IFN- }-\downarrow) \downarrow\end{array}$ & $\begin{array}{c}\text { dietary } \mathrm{Na}_{2} \mathrm{SeO}_{3} \\
0.6,0.8 \text { and } 1.0 \mathrm{mg} \mathrm{Se} / \mathrm{kg}\end{array}$ & 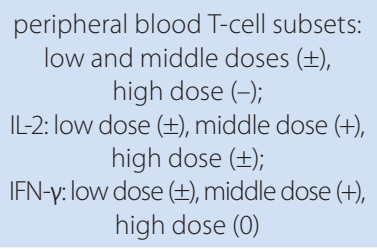 & not studied \\
\hline $\begin{array}{l}\text { Jebur et al. } \\
2014^{48}\end{array}$ & $\begin{array}{c}\text { rats } \\
\beta \text {-cyfluthrin, } \\
\text { oral gavage } \\
15 \mathrm{mg} / \mathrm{kg} \text { b.w. }(1 / 25 \\
\left.\text { LD } \mathrm{D}_{50}\right) \\
30 \text { days }\end{array}$ & $\begin{array}{l}\text { liver TBARS, LDH } \uparrow ; \\
\text { liver GSH, GPX, GR, SOD, } \\
\text { CAT, GST, AST, ALT, ALP } \downarrow\end{array}$ & $\begin{array}{c}\mathrm{Na}_{2} \mathrm{SeO}_{3} \text {, oral gavage } \\
200 \mu \mathrm{g} \mathrm{Se} / \mathrm{kg} \text { b.w. } \\
30 \text { days }\end{array}$ & $\begin{array}{c}\text { TBARS, GSH, GPX, GR, SOD, CAT, } \\
\operatorname{LDH}(+) ; \\
\text { AST, } \operatorname{ALT}, \operatorname{ALP}( \pm) \\
\text { GST }(0)\end{array}$ & $\begin{array}{c}\text { serum ALT, } \\
\text { TBARS } \downarrow ; \\
\text { serum GSH, } \\
\text { GPx, GR, } \\
\text { CAT, GST } \uparrow\end{array}$ \\
\hline $\begin{array}{l}\text { El-Demerdash } \\
\text { and Nasr } 2014^{15}\end{array}$ & $\begin{array}{c}\text { rats } \\
\text { diazinon, oral gavage } \\
10 \mathrm{mg} / \mathrm{kg} \mathrm{b.w} \text {. } \\
30 \text { days }\end{array}$ & $\begin{array}{c}\text { serum TBARS, ALT, AST, } \\
\text { ALP, LDH } \uparrow ; \\
\text { serum GSH, SOD, CAT, } \\
\text { GST, GPx, GR, AChE, } \\
\text { HDL-cholesterol } \downarrow ; \\
\text { serum total lipids, total } \\
\text { cholesterol, triglycerides, } \\
\text { LDL-cholesterol } \uparrow\end{array}$ & $\begin{array}{c}\mathrm{Na}_{2} \mathrm{SeO}_{3} \text {, oral gavage } \\
200 \mu \mathrm{g} \mathrm{Se} / \mathrm{kg} \mathrm{b.w.} \\
30 \text { days }\end{array}$ & all studied parameters $( \pm)$ & $\begin{array}{l}\text { TBARS } \downarrow ; \\
\text { GSH, CAT, } \\
\text { GST, GPX, } \\
\text { GR } \uparrow\end{array}$ \\
\hline $\begin{array}{l}\text { Acker and } \\
\text { Nogueira } \\
2014^{20}\end{array}$ & $\begin{array}{c}\text { rats } \\
\text { acephate, oral gavage } \\
140 \mathrm{mg} / \mathrm{kg} \\
\text { once }\end{array}$ & $\begin{array}{c}\text { plasma glucose, } \\
\text { corticosterone, } \\
\text { triglycerides } \uparrow ; \\
\text { liver tyrosine } \\
\text { aminotransferase } \uparrow ; \\
\text { cerebral AChE } \downarrow\end{array}$ & $\begin{array}{c}\text { synthetic organic } \\
\text { diphenyl diselenide, } \\
\text { oral gavage } \\
10 \text { or } 30 \mathrm{mg} / \mathrm{kg} \\
1 \mathrm{~h} \text { before acephate, once }\end{array}$ & $\begin{array}{c}\text { plasma glucose }( \pm) ; \\
\text { plasma corticosterone }(0) ; \\
\text { plasma triglycerides }(+) ; \\
\text { cerebral AChE }(0) ; \\
\text { liver tyrosine aminotransferase: } \\
\text { lower dose }(0) \text {, higher dose }( \pm)\end{array}$ & none \\
\hline
\end{tabular}

$\downarrow$ - decrease; $\uparrow$ - increase; (+) - full protection; $( \pm)$ - partial protection; (0) - lack of protection; (-) - intensification of harmful effects; GPx - glutathione peroxidase; GR - glutathione reductase; TrxR - thioredoxin reductase; TBARS - thiobarbituric acid-reactive substances; ALT - alanine aminotransferase; AST - aspartate aminotransferase; LDH - lactate dehydrogenase; GSH - reduced glutathione; ALP - alkaline phosphatase; SOD - superoxide dismutase; CAT - catalase; AChE - acetylcholinesterase.

activity only the low dose, and in the case of GSH only the high one, were found to be effective. ${ }^{51}$

In vitro experiments have also shown the efficacy of selenium nanoparticles. This form was proved to prevent DNA damage and cell death in lymphocytes exposed to UVB radiation. ${ }^{52}$ Another study performed on cardiomyoblast $\mathrm{H} 9 \mathrm{c} 2$ cells revealed the occurrence of changes in the antioxidant level as well as in mitochondrial functions during ischemia and reperfusion which were prevented by selenium in the form of selenium incorporated guar gum nanoparticles. ${ }^{53}$
Natural selenium forms have also been found to show a protective effect under in vitro conditions. Two seleniumenriched medicines of herbal origin (IMOD and Angipars) (Rose Pharmed Biotechnology Co., Iran) were studied in an experiment performed on human lymphocytes. Both substances prevented the toxicity of an organophosphorus pesticide - chlorpyrifos. The beneficial influence included the amelioration of the chlorpyrifos-induced increase in TNF- $\alpha$ and reduction in cell apoptosis and necrosis. ${ }^{54}$ 
Table 8. Protective effect of selenium against negative effects caused by pathological condition

\begin{tabular}{|c|c|c|c|c|c|}
\hline $\begin{array}{l}\text { Authors, } \\
\text { citation } \\
\text { number }\end{array}$ & $\begin{array}{l}\text { Animals } \\
\text { pathological } \\
\text { condition }\end{array}$ & Harmful effects & $\begin{array}{l}\text { Selenium form, } \\
\text { dose, } \\
\text { method and time } \\
\text { of administration }\end{array}$ & $\begin{array}{l}\text { Effects of selenium } \\
\text { co-administration }\end{array}$ & $\begin{array}{l}\text { Effects of } \\
\text { Se itself }\end{array}$ \\
\hline $\begin{array}{l}\text { Akil et al. } \\
2011^{49}\end{array}$ & $\begin{array}{c}\text { rats } \\
\text { acute swimming } \\
\text { exercise } \\
\text { after the end } \\
\text { of experiment period, } \\
\text { once for } 30 \mathrm{~min}\end{array}$ & $\begin{array}{c}\text { plasma MDA and lactate, } \\
\text { erythrocyte GSH, } \\
\text { serum SOD and GPx } \uparrow\end{array}$ & $\begin{array}{c}\mathrm{Na}_{2} \mathrm{SeO}_{3} \\
200 \mu \mathrm{g} / \text { day, intraperitoneally } \\
4 \text { weeks }\end{array}$ & $\begin{array}{c}\text { plasma MDA and lactate }( \pm) ; \\
\text { erythrocyte GSH, serum SOD } \\
\text { and GPx further } \uparrow\end{array}$ & none \\
\hline $\begin{array}{l}\text { Prigol et al. } \\
2009^{16}\end{array}$ & $\begin{array}{c}\text { mice } \\
\text { acute swimming } \\
\text { exercise } \\
\text { after Se-treatment, } \\
\text { for } 20 \text { min; euthanized } \\
1 \text { h or } 24 \text { h after } \\
\text { exercise }\end{array}$ & $\begin{array}{l}\text { euthanized after } 1 \mathrm{~h} \text { : } \\
\text { skeletal muscle MDA } \\
\text { and vitamin C, lung } \\
\text { MDA and CAT } \uparrow ; \\
\text { euthanized after } 24 \mathrm{~h} \text { : } \\
\text { skeletal muscle MDA } \\
\text { and vitamin C } \uparrow\end{array}$ & $\begin{array}{l}\text { synthetic organic } \\
\text { diphenyl diselenide } \\
\text { pretreatment } \\
5 \mathrm{mg} / \mathrm{kg} \text {, orally } \\
7 \text { days }\end{array}$ & $\begin{array}{c}\text { euthanized after } 1 \mathrm{~h} \text { : } \\
\text { skeletal muscle and lung } \\
\text { MDA }(+) ; \\
\text { skeletal muscle vitamin C, } \\
\text { lung CAT }( \pm) ; \\
\text { euthanized after } 24 \mathrm{h:} \\
\text { skeletal muscle MDA }(+) ; \\
\text { skeletal muscle vitamin C }( \pm)\end{array}$ & $\begin{array}{c}\text { after } 1 \mathrm{~h} \text { : } \\
\text { muscle } \\
\text { MDA } \downarrow \\
\text { after } 24 \mathrm{~h} \text { : } \\
\text { muscle } \\
\text { MDA and } \\
\text { vitamin } C \downarrow \text {; } \\
\text { lung } \\
\text { vitamin } \subset \uparrow\end{array}$ \\
\hline $\begin{array}{l}\text { Ghazi Harsini } \\
\text { et al. } 2012^{4}\end{array}$ & $\begin{array}{l}\text { chicken } \\
\text { heat stress } \\
4 \text { weeks }\end{array}$ & $\begin{array}{l}\text { serum glucose, uric acid } \\
\text { and copper, skeletal } \\
\text { muscle MDA and SOD } \uparrow ; \\
\text { serum iron and zinc } \downarrow\end{array}$ & $\begin{array}{c}\text { dietary selenomethionine } \\
0.5 \text { or } 1 \mathrm{mg} \text { of } \mathrm{Se} / \mathrm{kg}\end{array}$ & $\begin{array}{c}\text { lower dose: } \\
\text { skeletal muscle MDA, } \\
\text { serum glucose }( \pm) ; \\
\text { serum uric acid, copper, } \\
\text { iron and zinc }(0) ; \\
\text { skeletal muscle SOD }(-) \\
\text { higher dose: } \\
\text { skeletal muscle MDA, serum } \\
\text { glucose, copper } \\
\text { and uric acid }( \pm) ; \\
\text { serum iron and zinc }(0) ; \\
\text { skeletal muscle SOD }(-)\end{array}$ & none \\
\hline $\begin{array}{l}\text { Ghodbane } \\
\text { et al. } 2011^{50}\end{array}$ & $\begin{array}{l}\text { rats } \\
\text { static magnetic field } \\
128 \mathrm{mT} / 1 \mathrm{~h} / \text { day for the } \\
\text { last } 5 \text { consecutive days } \\
\text { of Se-administration }\end{array}$ & $\begin{array}{c}\text { kidney and muscle } \\
\text { GPx } \downarrow ; \\
\text { kidney, muscle and brain } \\
\text { Se level } \downarrow\end{array}$ & $\begin{array}{c}\mathrm{Na}_{2} \mathrm{SeO}_{3} \\
0.2 \mathrm{mg} / \mathrm{L}, \text { in drinking water } \\
\text { for } 4 \text { weeks }\end{array}$ & $\begin{array}{c}\text { kidney and muscle GPx (+); } \\
\text { kidney, muscle and brain Se } \\
\text { level (+) }\end{array}$ & $\begin{array}{l}\text { liver and } \\
\text { muscle } \\
\text { GPx } \uparrow\end{array}$ \\
\hline
\end{tabular}

$\downarrow$-decrease; $\uparrow$ - increase; (+) - full protection; $( \pm)$ - partial protection; (0) - lack of protection; (-) - intensification of harmful effects; MDA - malonyldialdehyde; CAT - catalase; SOD - superoxide dismutase; GPx - glutathione peroxidase; GSH - reduced glutathione.

\section{Protective properties of selenium: Human model research}

Diverse human studies have also revealed the beneficial effects of selenium supplementation.

In young children (4.4-5.4 years) in rural Bangladesh, an inverse relationship between the exposure to cadmium (evaluated by the assay of its urinary level) and glomerular filtration rate was found, particularly in girls. This effect was alleviated in subjects with higher urinary selenium, which led the authors to suggest that higher Se-status seemed to exert a protective influence against cadmium nephrotoxicity. ${ }^{55}$

An interesting study on 933 mother-newborn pairs, performed in China, revealed that umbilical cord serum manganese was related to the risk of lower Neonatal Behavioral Neurological Assessment rank. However, this effect was alleviated in the cases where umbilical cord serum selenium was higher. The authors suggested that selenium supplementation might be considered in pregnant women, particularly in regions of low environmental selenium level. ${ }^{56}$
Based on a study involving cancerous patients subjected to cisplatin therapy, Ghorbani et al. suggested that selenium might prevent the renal toxicity of the drug. They found that acute kidney failure occurred in $11.5 \%$ of patients treated with cisplatin, whereas in those pretreated with a single selenium tablet (400 mcg), no such cases were observed. ${ }^{57}$ Similarly, Mix et al. observed some protective influence of selenium treatment (selenomethionine, 1 week before as well as during therapy) in patients with inoperable, stage III non-small cell lung cancer undergoing concurrent chemoradiation (radiation, paclitaxel and cisplatin). ${ }^{23}$

\section{Conclusions}

In conclusion, the presented studies make it possible to suggest that selenium seems to be one of the most appealing agents to be examined in relation to its protective role against the toxic effects induced by different harmful factors, both chemical and physical. But it must be 
emphasized that its effect depends on many factors, such as its chemical form as well as the applied dose and experimental model, so supplementation must be performed taking proper precautions to obtain the best results and avoid the toxicity of selenium itself. $5,10,24,36$

\section{References}

1. Agarwal R, Behari JR. Effect of selenium pretreatment in chronic mercury intoxication in rats. Bull Environ Contam Toxicol. 2007;79:306-310.

2. Broome CS, McArdle F, Kyle JA, et al. An increase in selenium intake improves immune function and poliovirus handling in adults with marginal selenium status. Am J Clin Nutr. 2004;80:154-162.

3. Liu Y, Liu Q, Ye G, et al. Protective effects of Selenium-enriched probiotics on carbon tetrachloride-induced liver fibrosis in rats. J Agric Food Chem. 2015;63:242-249.

4. Ghazi Harsini S, Habibiyan M, Moeini MM, Abdolmohammadi AR. Effects of dietary selenium, vitamin $E$, and their combination on growth, serum metabolites, and antioxidant defense system in skeletal muscle of broilers under heat stress. Biol Trace Elem Res. 2012;148:322-330.

5. Ghosh P, Bhattacharjee A, Basu A, Singha Roy S, Bhattacharya S. Attenuation of cyclophosphamide-induced pulmonary toxicity in Swiss albino mice by naphthalimide-based organoselenium compound 2-(5-selenocyanatopentyl)-benzo[de]isoquinoline 1,3-dione. Pharm Biol. 2015;53:524-532.

6. McKelvey SM, Horgan KA, Murphy RA. Chemical form of selenium differentially influences DNA repair pathways following exposure to lead nitrate. J Trace Elem Med Biol. 2015;29:151-169.

7. Ungvári É, Monori I, Megyeri A, et al. Protective effects of meat from lambs on selenium nanoparticle supplemented diet in a mouse model of polycyclic aromatic hydrocarbon-induced immunotoxicity. Food Chem Toxicol. 2014;64:298-306.

8. Han XJ, Xiao YM, Ai BM, Hu XX, Wei Q, Hu QS. Effects of organic selenium on lead-induced impairments of spatial learning and memory as well as synaptic structural plasticity in rats. Biol Pharm Bull. 2014;37:466-474.

9. Chakraborty P, Roy SS, Sk UH, Bhattacharya S. Amelioration of cisplatin-induced nephrotoxicity in mice by oral administration of diphenylmethyl selenocyanate. Free Radic Res. 2011;45:177-187.

10. Wang D, Zhao Y, Sun Y, Yang X. Protective effects of Ziyang tea polysaccharides on $\mathrm{CCl}_{4}$-induced oxidative liver damage in mice. Food Chem. 2014;143:371-378.

11. Nuttall KL. Evaluating selenium poisoning. Ann Clin Lab Sci. 2006;36:409-420.

12. Falandysz J, Lipka K. Selenium in mushrooms. Roczn PZH. 2006;57:217233 [in Polish].

13. MacFarquhar JK, Broussard DL, Melstrom P, et al. Acute selenium toxicity associated with a dietary supplement. Arch Intern Med. 2010;170:256-261. doi: 10.1001/archinternmed.2009.495

14. Li JL, Jiang CY, Li S, Xu SW. Cadmium induced hepatotoxicity in chickens (Gallus domesticus) and ameliorative effect by selenium. Ecotoxicol Environ Saf. 2013;96:103-109.

15. El-Demerdash FM, Nasr HM. Antioxidant effect of selenium on lipid peroxidation, hyperlipidemia and biochemical parameters in rats exposed to diazinon. J Trace Elem Med Biol. 2014;28:89-93.

16. Prigol M, Luchese C, Nogueira CW. Antioxidant effect of diphenyl diselenide on oxidative stress caused by acute physical exercise in skeletal muscle and lungs of mice. Cell Biochem Funct. 2009;27:216-222.

17. Vargas LM, Soares MB, Izaguirry AP, et al. Cadmium inhibits the ovary $\delta$-aminolevulinate dehydratase activity in vitro and ex vivo: Protective role of seleno-furanoside. J Appl Toxicol. 2013;33:679-684.

18. Hassanin KM, Abd El-Kawi SH, Hashem KS. The prospective protective effect of selenium nanoparticles against chromium-induced oxidative and cellular damage in rat thyroid. Int J Nanomedicine. 2013;8:1713-1720.

19. Glaser V, Moritz B, Schmitz A, et al. Protective effects of diphenyl diselenide in a mouse model of brain toxicity. Chem Biol Interact. 2013;206:18-26.

20. Acker $\mathrm{Cl}$, Nogueira CW. Diphenyl diselenide protects against meta- bolic disorders induced by acephate acute exposure in rats. Environ Toxicol. 2014;29:665-671.

21. Serafín Muñoz AH, Wrobel K, Gutierrez Corona JF, Wrobel K. The protective effect of selenium inorganic forms against cadmium and silver toxicity in mycelia of Pleurotus ostreatus. Mycol Res. 2007;111:626632.

22. Song E, Su C, Fu J, et al. Selenium supplementation shows protective effects against patulin-induced brain damage in mice via increases in GSH-related enzyme activity and expression. Life Sci. 2014;109:37-43.

23. Mix M, Ramnath N, Gomez J, et al. Effects of selenomethionine on acute toxicities from concurrent chemoradiation for inoperable stage III non-small cell lung cancer. World J Clin Oncol. 2015;6:156-165.

24. Singha Roy S, Ghosh P, Sk UH, et al. Naphthalimide based novel organoselenocyanates: Finding less toxic forms of selenium that would retain protective efficacy. Bioorg Med Chem Lett. 2010;20:6951-6955.

25. Wilhelm EA, Bortolatto CF, Nogueira CW. p-Methoxyl-diphenyl diselenide protects against cisplatin-induced renal toxicity in mice. Food Chem Toxicol. 2012;50:1187-1193.

26. Sk UH, Bhattacharya S. Prevention of cadmium induced lipid peroxidation, depletion of some antioxidative enzymes and glutathione by a series of novel organoselenocyanates. Environ Toxicol Pharmacol. 2006;22:298-308.

27. Sevcikova L, Pechova A, Pavlata $L$, et al. The effect of various forms of selenium supplied to pregnant goats on the levels of selenium in the body of their kids at the time of weaning. Biol Trace Elem Res. 2011;143:882-892.

28. Malhotra S, Welling MN, Mantri SB, Desai K. In vitro and in vivo antioxidant, cytotoxic, and anti-chronic inflammatory arthritic effect of selenium nanoparticles. J Biomed Mater Res Part B. 2016;104:9931003.

29. Kalishwaralal K, Jeyabharathi S, Sundar K, Muthukumaran A. Comparative analysis of cardiovascular effects of selenium nanoparticles and sodium selenite in zebrafish embryos. Artif Cells Nanomed Biotechnol. 2015;20:1-7.

30. Yazici A, Sogutlu-Sari E, Yay A, et al. The protective effect of selenium in cisplatin-related retinotoxicity. Cutan Ocul Toxicol. 2014;33:327-332.

31. Rezvanfar MA, Rezvanfar MA, Shahverdi AR, et al. Protection of cisplatin-induced spermatotoxicity, DNA damage and chromatin abnormality by selenium nano-particles. Toxicol Appl Pharmacol. 2013;266:356-365.

32. Gürgen SG, Erdoğan D, Elmas C, Kaplanoğlu GT, Ozer C. Chemoprotective effect of ascorbic acid, a-tocopherol, and selenium on cyclophosphamide-induced toxicity in the rat ovarium. Nutrition. 2013:29:777-784.

33. Danesi F, Malaguti M, Di Nunzio M, Maranesi M, Biagi PL, Bordoni A. Counteraction of adriamycin-induced oxidative damage in rat heart by selenium dietary supplementation. J Agric Food Chem. 2006;54:1203-1208.

34. Saied NM, Hamza AA. Selenium ameliorates isotretinoin-induced liver injury and dyslipidemia via antioxidant effect in rats. Toxicol Mech Methods. 2014;24:433-437.

35. Mossa ATH, Heikal TM, Mohafrash SMM. Lipid peroxidation and oxidative stress in rat erythrocytes induced by aspirin and diazinon: The protective role of selenium. Asian Pac J Trop Biomed. 2014;4(Suppl 2): S603-S609.

36. Chen K, Yuan S, Chen J, et al. Effects of sodium selenite on the decreased percentage of T cell subsets, contents of serum IL-2 and IFN- $\gamma$ induced by aflatoxin $B_{1}$ in broilers. Res Vet Sci. 2013;95:143-145.

37. El-Boshy ME, Risha EF, Abdelhamid FM, Mubarak MS, Hadda TB. Protective effects of selenium against cadmium induced hematological disturbances, immunosuppressive, oxidative stress and hepatorenal damage in rats. J Trace Elem Med Biol. 2015;29:104-110.

38. Viezeliene D, Beekhof P, Gremmer E, et al. Selective induction of IL-6 by aluminum-induced oxidative stress can be prevented by selenium. J Trace Elem Med Biol. 2013;27:226-229.

39. Lakshmi BV, Sudhakar M, Prakash KS. Protective effect of selenium against aluminum chloride-induced Alzheimer's disease: Behavioral and biochemical alterations in rats. Biol Trace Elem Res. 2015;165:67-74.

40. Prasad KS, Selvaraj K. Biogenic synthesis of selenium nanoparticles and their effect on As(III)-induced toxicity on human lymphocytes. Biol Trace Elem Res. 2014;157:275-283. 
41. Xu Z, Wang Z, Li JJ, et al. Protective effects of selenium on oxidative damage and oxidative stress related gene expression in rat liver under chronic poisoning of arsenic. Food Chem Toxicol. 2013;58:1-7.

42. Baş $H$, Kalender $Y$, Pandir D, Kalender S. Effects of lead nitrate and sodium selenite on DNA damage and oxidative stress in diabetic and non-diabetic rat erythrocytes and leucocytes. Environ Toxicol Pharmacol. 2015;39:1019-1026.

43. Soudani N, Troudi A, Bouaziz H, Ben Amara I, Boudawara T, Zeghal N. Cardioprotective effects of selenium on chromium (VI)-induced toxicity in female rats. Ecotoxicol Environ Saf. 2011;74:513-520.

44. Soudani N, Troudi A, Ben Amara I, Bouaziz H, Boudawara T, Zeghal N. Ameliorating effect of selenium on chromium (VI)induced oxidative damage in the brain of adult rats. J Physiol Biochem. 2012;68:397-409.

45. Ding M, Potter JJ, Liu X, Torbenson MS, Mezey E. Selenium supplementation decreases hepatic fibrosis in mice after chronic carbon tetrachloride administration. Biol Trace Elem Res. 2010;133:83-97.

46. Ali MA, Aly EM, Elawady Al. Effectiveness of selenium on acrylamide toxicity to retina. Int J Ophthalmol. 2014;7:614-620.

47. Liao S, Shi D, Clemons-Chevis $C L$, et al. Protective role of selenium on aflatoxin b1-induced hepatic dysfunction and apoptosis of liver in ducklings. Biol Trace Elem Res. 2014;162:296-301.

48. Jebur AB, Nasr HM, El-Demerdash FM. Selenium modulates $\beta$-cyfluthrin-induced liver oxidative toxicity in rats. Environ Toxicol. 2014;29:1323-1329.

49. Akil M, Gurbuz U, Bicer M, Sivrikaya A, Mogulkoc R, Baltaci AK. Effect of selenium supplementation on lipid peroxidation, antioxidant enzymes, and lactate levels in rats immediately after acute swimming exercise. Biol Trace Elem Res. 2011;142:651-659.

50. Ghodbane S, Amara S, Garrel C, et al. Selenium supplementation ameliorates static magnetic field-induced disorders in antioxidant status in rat tissues. Environ Toxicol Pharmacol. 2011;31:100-106.

51. Barayuga SM, Pang X, Andres MA, Panee J, Bellinger FP. Methamphetamine decreases levels of glutathione peroxidases 1 and 4 in SH-SY5Y neuronal cells: Protective effects of selenium. Neurotoxicology. 2013;37:240-246.

52. Prasad KS, Patel H, Patel T, Patel K, Selvaraj K. Biosynthesis of Se nanoparticles and its effect on UV-induced DNA damage. Colloids Surf B Biointerfaces. 2013;103:261-266.

53. Soumya RS, Vineetha VP, Salin Raj P, Raghu KG. Beneficial properties of selenium incorporated guar gum nanoparticles against ischemia/ reperfusion in cardiomyoblasts (H9c2). Metallomics. 2014;6:2134-2147.

54. Navaei-Nigjeh $M$, Asadi $H$, Baeeri $M$, et al. In vitro protection of human lymphocytes from toxic effects of chlorpyrifos by selenium-enriched medicines. Iran J Basic Med Sci. 2015;18:284-291.

55. Skröder H, Hawkesworth S, Kippler M, et al. Kidney function and blood pressure in preschool-aged children exposed to cadmium and arsenic - potential alleviation by selenium. Environ Res. 2015;140:205-213.

56. Yang X, Bao Y, Fu H, Li L, Ren T, Yu X. Selenium protects neonates against neurotoxicity from prenatal exposure to manganese. PLoS One. 2014;9:e86611.

57. Ghorbani A, Omidvar B, Parsi A. Protective effect of selenium on cisplatin induced nephrotoxicity: A double-blind controlled randomized clinical trial. J Nephropathol. 2013;2:129-134. 